\title{
Resistência de ratos à peritonite fecal quando submetidos a esplenectomia e auto-implante do baço no retroperitônio ${ }^{1}$
}

\author{
Rats resistence to fecal peritonitis when subjected to total spleenectomy and auto- \\ implant of the spleen in the retroperitoniun
}

\author{
Darlan de Medeiros Kestering², Armando José d’Acampora ${ }^{3}$, Débora Cadore Farias ${ }^{4}$, Sandro Polidoro Berni Brum², \\ Jorge Bins Ely ${ }^{3}$ \\ 1. Trabalho realizado no Laboratório de Técnica Operatória e Cirurgia Experimental da Universidade do Sul de Santa Catarina (UNISUL). \\ 2. Professor da Disciplina de Bases da Clínica Cirúrgica e Cirurgia Experimental da UNISUL. Mestre em Ciências Médicas pela Universidade \\ Federal de Santa Catarina (UFSC). \\ 3. Professor de Técnica Operatória e Cirurgia Experimental da UFSC.Doutor em Medicina pela UNIFESP-EPM. \\ 4. Estudante de Medicina, UFSC.
}

\section{RESUMO}

Objetivo: O estudo foi desenvolvido para avaliar os efeitos do autotransplante esplênico na proteção contra sepse abdominal em ratos Wistar jovens e adultos. Métodos: Foram utilizados 54 ratos Wistar jovens e adultos (90 e 180 dias respectivamente) sendo distribuídos em 3 grupos: Grupo Sham, onde os animais eram submetidos a laparotomia com manipulação de alças apenas ( $\mathrm{n}=6$ animais jovens adultos), Grupo Esplenectomia, no qual os animais eram submetidos a esplenectomia total (n=10 animais jovens e adultos) e Grupo Auto-implante, onde os animais eram submetidos a esplenectomia total e um terço do baço era implantado em uma bolsa no retroperitônio ( $\mathrm{n}=10$ animais jovens e adultos). Após três meses os animais eram submetidos a nova laparotomia com ligadura e perfuração do ceco para estimular a sepse abdominal e acompanhados até o momento do óbito para estabelecimento de uma curva de mortalidade. Resultados: Houve recuperação do baço implantado em todos os animais. Não houve diferença significativa entre o tempo de óbito entre os grupos. Os animais jovens aparentemente tiveram uma melhor resposta embora não estatisticamente significativa. Conclusão: Este estudo demonstrou que o auto-implante de baço no retroperitônio não provê proteção efetiva contra sepse abdominal em comparação aos ratos esplenectomizados.

Descritores: Esplenectomia. Peritonite. Ratos.

\begin{abstract}
Purpose: This study was developed to evaluated the effects of spleen transplants in the protection against abdominal sepsis in young and old Wistar rats. Methods: Fifty-four young and old Wistar rats were utilized (90 and 180 days respectively) being distributed in three groups as follows: Sham Group, where the animal were submitted to laparotomy with manipulation of only intestine ( $\mathrm{n}=12$ young and adult animals), Spleenectomy Group, in which the animals were subjected to total spleenectomy ( $\mathrm{n}=20$ young and adult animals) and an Auto-implant Group, where the animals were subjected to total spleenectomy and a thrird of the spleen was implanted in a bag in the retroperitonium ( $\mathrm{n}=22$ young and adult animals). After three months the animals were subjected to a new laparotomy with binding and caecum perfuration to stimulate abdominal sepsis and were accompanied until the moment of death to establish a mortality curve. Results: There was recuperation of the spleen implanted in all animals. There was no significant difference in the time of death among the groups. The young animals apparently had a better response, however it was not statistically significant. Conclusion: This study demonstrated that spleen implant in the retroperitonium do not prove to be an effective protection against abdominal sepsis in comparison with the spleenectomized rats.
\end{abstract}

Key words: Splenectomy. Peritonitis. Rats.(Footnotes)

\section{Introdução}

O baço foi durante muito tempo um desafio para os pesquisadores, sendo considerado um órgão misterioso e sem função conhecida, portanto, sua remoção cirúrgica conseqüente ao trauma ou outras doenças, não provocaria dano maior ao paciente. ${ }^{1,2}$ Publicações sobre o assunto, como os estudos de Morris e Bullock, em 1919, sugeriam que a ausência do baço poderia estar associada com o aumento da susceptibilidade à infecção, incentivando a pesquisa sobre o tema. ${ }^{3}$ Alguns anos após, o primeiro relato de infecção pós esplenectomia foi realizado por O’Donnell em 1929(citado por Sumaraju e col., 2001) ${ }^{4}$ o que não levou à diminuição da retirada do órgão, e a esplenectomia total 
continuou sendo amplamente utilizada como tratamento de escolha para o trauma abdominal com lesão de baço e para os distúrbios hematológicos. No entanto, somente e a partir da publicação de King e Shumacker (1952) na qual foram relatados 5 casos de infecção grave (sepse) em crianças submetidas à esplenectomia por esferocitose, onde duas delas evoluíram para o óbito ${ }^{5}$, é que o baço passou a ter despertada sua importância quanto a conservação. Decorre destes fatos o interesse pelo autotransplante de tecido esplênico, o qual despertou interesse clínico e as pesquisas foram estimuladas principalmente, depois que Person e col. (1978) documentaram algum grau de função esplênica em crianças com esplenose após esplenectomia por trauma. ${ }^{6}$ Numerosos estudos versando sobre o autotransplante de fragmentos esplênicos são descritos na literatura como alternativa em trauma esplênico quando a preservação é impossível. Entretanto, nem a estrutura nem a função destes fragmentos transplantados foram estudadas satisfatoriamente, principalmente devido ao fato que biópsias ou outras técnicas invasivas em humanos não se justificam para este fim, por questões éticas. Por isso dados de modelos animais se tornam importantes para o entendimento dos mecanismos da regeneração esplênica. ${ }^{6}$ Também têm sido amplamente divulgado na literatura os aspectos técnicos relativos ao implante esplênico autólogo heterotópico. De acordo com a maioria dos autores, este procedimento é simples, e não está associado à complicações maiores. ${ }^{7-11}$ Os fragmentos esplênicos têm capacidade de regeneração sem necessidade de anastomose vascular, após um período inicial de necrose. ${ }^{11}$ Diversos métodos de preparação dos fragmentos esplênicos a serem transplantados já foram descritos, bem como uma grande variedade de regiões topográficas para realizar o autotransplante. No entanto, a maioria dos autores concorda que a massa de tecido a ser implantada, deva ser de aproximadamente $30 \%$ do volume original do baço. ${ }^{9,10}$ Embora tenham sido efetuados diversos estudos com autoimplante esplênico os resultados têm se mostrado bastante controversos tanto em relação a proteção oferecida por estes implantes como em relação ao sítio de implantação. ${ }^{12-15}$ Devido a esta contradição de resultados e a escassez de trabalhos avaliando o autotransplante no retroperitônio se idealizou este estudo com objetivo de avaliar o autotransplante esplênico na evolução da sepse abdominal em ratos Wistar jovens e adultos.

\section{Métodos}

Foram utilizados um total de 54 ratos Wistar jovens e adultos com idade aproximada de 90 e 180 dias respectivamente, da linhagem WISTAR (Rattus norvegicus albinus, Rodentia mammalia), provenientes do Biotério Central da Universidade do Sul de Santa Catarina (UNISUL). Os animais foram distribuídos em 3 grupos e cada grupo distribuído em 2 subgrupos:

Grupo sham - 12 ratos, 6 ratos jovens e 6 ratos adultos. Os animais foram submetidos a laparotomia sem esplenectomia com manipulação das vísceras. Após 12 semanas foram submetidos à ligadura e perfuração do ceco.
Grupo esplenectomia - 20 ratos, 10 ratos jovens e 10 adultos. Foram submetidos a esplenectomia total e 12 semanas após procedeu-se à ligadura e perfuração do ceco.

Grupo autotransplante - 22 ratos, 10 ratos jovens e 12 adultos. Foram submetidos a esplenectomia total sendo o baço dividido em 3 partes iguais sendo o fragmento medial implantado em uma bolsa confeccionada no retroperitônio com poliglactina 910 4.0. Todos os animais foram avaliados clinicamente, levando-se em conta o tempo percorrido entre a ligadura e punção do ceco e o óbito causado pela sepse.

Os dados foram analisados com auxílio do programa SPSS-WINDOWS versão 8.0, 1997. Statistical Package for Social Sciences. Foram calculadas proporções para variáveis categóricas e médias para variáveis contínuas, segundo tipo de cirurgia. Diferenças entre proporções foram testadas através do teste qui-quadrado de Pearson e as diferenças entre médias, através do teste t de Student e da análise de variância. Os valores de p foram considerados como significantes quando iguais ou menores que 0,05 ou $5 \%$ (Figuras 1 e 2 ).

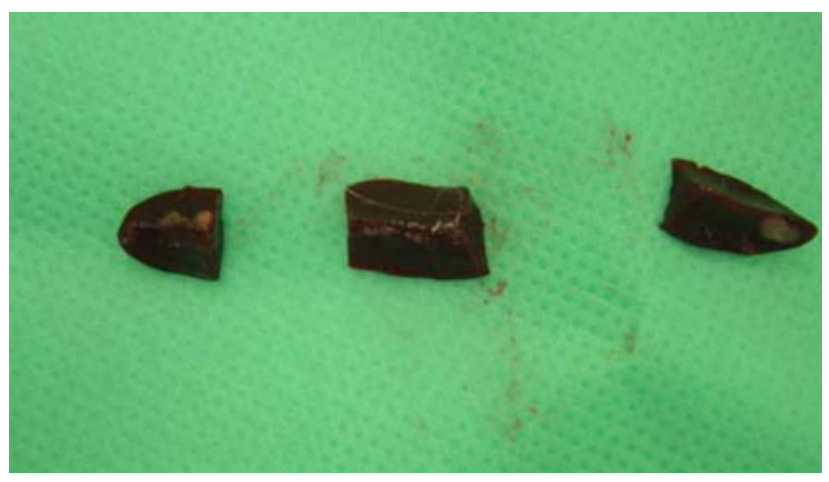

FIGURA 1 - Divisão do baço em 3 fragmentos para implantação do fragmento medial.

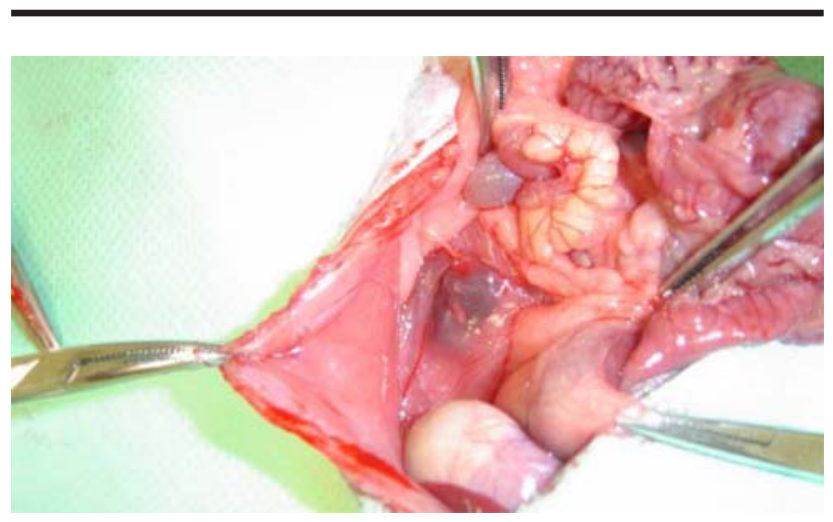

FIGURA 2 - Aspecto final do baço implantado no retroperitônio.

\section{Resultados}

Dos 54 ratos do início do experimento foram analisados um total de 50 animais. Ocorreram 2 óbitos no subgrupo 02, 1 óbito no subgrupo 05 e 1 óbito no subgrupo 03. Estes óbitos 
ocorreram no pós-operatório imediato do primeiro procedimento cirúrgico antes de completas as 12 semanas, quando seria realizada a perfuração e ligadura do ceco e foram descartados (Tabelas 1 e 2).

TABELA 1 - Análise estatística comparativa do tempo (em horas) decorrido para o óbito entre os grupos autotransplante e esplenectomia.

\begin{tabular}{lccr}
\hline Procedimento cirúrgico & Número de animais & $\%$ & Média \\
\hline Autotransplante & 21 & 42 & 42,90 \\
Esplenectomia & 19 & 38 & 47,42 \\
Shan & 10 & 20 & 31,90 \\
\hline Total & 50 & 100 & \\
\hline
\end{tabular}

$\mathrm{p}=0,653$

TABELA 2 - Análise estatística comparativa do tempo decorrido para o óbito nos ratos submetidos ao autotransmplante em relação a idade.

\begin{tabular}{lccr}
\hline Idade & Número de animais & $\%$ & Média \\
\hline Jovem & 9 & 42,86 & 47,00 \\
Adulto & 12 & 57,14 & 39,83 \\
\hline Total & 21 & 100 & \\
\hline
\end{tabular}

$\mathrm{p}=0,925$

\section{Discussão}

O papel do baço no sistema imunológico tem sido objeto de muitos estudos, sabendo-se da sua importância quando é referida a defesa orgânica relacionada à invasão de microorganismos. O baço tem a capacidade de capturar partículas reconhecidas como estranhas ao organismo e disponibilizar células, como os macrófagos, para que possam fagocitá-las ${ }^{16,17}$, liberando a economia, por filtração específica, destas partículas. Para que esta função seja adequadamente exercida, a manutenção da arquitetura esplênica é considerada como essencialmente importante quando da realização dos autotransmplantes, no mínimo para que conservem esta função, quiçá a mais nobre do órgão. A maior parte dos estudos experimentais realizados com autotransplante esplênico, analisou a resistência dos animais à infecção específica por pneumococos ${ }^{7,10,18,19}$ ou procurou demonstrar a capacidade de captura de partículas anormais marcadas sob radioatividade ${ }^{20,21}$ não tendo sido encontrado estudo que analisasse a resistência à sepse abdominal utilizando-se do mesmo método executado no presente estudo. Diversos autores têm demonstrado que os fragmentos de baço podem ser transplantados, e conseguem manter a mesma estrutura do baço original com uma zona marginal funcionante. ${ }^{8,18,22-24}$. A grande e contínua discussão continua sendo em torno do polêmico local privilegiado e definitivo para o implante destes segmentos esplênicos. Inúmeras tentativas de determinação de uma localização definitiva para o implante do baço foram aventadas, e ainda hoje alguns autores têm tentado fixar uma localização ideal para o autotransplante esplênico, demonstrando que o melhor lugar seria em situação onde o implante permanecesse dentro da cavidade peritoneal, com preferência para o grande omento, de maneira a manter o fragmento envolvido, de alguma forma, com a circulação portal. ${ }^{10,11,19,21,25-28}$ Acredita-se, no entanto, que nesta localização, ou seja, no grande omento, ocorram alguns problemas do ponto de vista de investigação, não só anatômico (haja vista a textura do baço ser semelhante à textura do grande omento), quanto fisiológico, onde um implante de um tecido de densidade semelhante, é colocado dentro de uma grande massa de tecido adiposo cuja consistência é de difícil caracterização aos exames de imagem, o que certamente interferirá com estes exames que envolvam imagens ou seguimento de células marcadas. Macroscopicamente, torna-se difícil a identificação do segmento implantado em uma quantidade apreciável de tecido adiposo frouxo. Esta constatação demonstra o que é notado em praticamente todos os estudos, onde o seguimento do implante é realizado de maneira clínica, pela melhor ou pior sobrevida dos animais ou pela intensidade e gravidade da infecção provocada, tendo em vista unicamente a evolução clínica dos animais até a ocorrência do óbito. O presente estudo foi iniciado após a observação desta polêmica na literatura consultada quanto à efetividade ou não de ação do tecido esplênico auto-implantado, preferindo-se a utilização de um modelo de sepse já testado no meio, para comparar grupos e tentar viabilizar uma resposta positiva ou não em relação à sobrevida dos animais com e sem esplenectomia e autotransplante. Quando o baço foi implantado no omento e em outros locais dentro da cavidade peritonial, os resultados encontrados na literatura mostram-se totalmente controversos, para não dizer contraditórios. Encontrou-se resultados, em alguns estudos que, aparentemente, têm demonstrado falha do enxerto na pretensa proteção contra sepse pós esplenectomia quando implantados nesta localização. ${ }^{20,29-33} \mathrm{O}$ experimento aqui relatado, não demonstrou superioridade na sobrevida dos ratos submetidos ao autotransmplante no retroperitônio em comparação aos ratos esplenectomizados quando expostos a peritonite. Deve-se frisar que todos animais do grupo utilizado como sham (sem esplenectomia total sem autotransplante e peritonite) foram aqueles onde o óbito ocorreu mais rapidamente (tabela 2), sugerindo que o baço realmente faça diferença quanto a uma mais intensa resposta inflamatória da sepse, sem que o objetivo fosse esclarecer qual a função responsável por esta diferença. É claro que em virtude do pequeno tamanho da amostra nada de concreto se pode afirmar. Como nos animais esplenectomizados o óbito ocorreu em um tempo mais longo, embora estatisticamente não significante, pode-se inferir novamente que a presença do baço realmente tenha função ativa na resposta inflamatória sistêmica. Com relação a idade dos animais alguns estudos têm demonstrado um melhor comportamento dos enxertos em animais jovens. ${ }^{18,33}$ Comparativamente aos dados da literatura quanto a este estudo, observou-se uma aparente melhor resposta nos animais jovens, embora não estatisticamente significativa, o que talvez possa ser demonstrado com uma amostra maior. O fato deste estudo não ter demonstrado melhora da sobrevida dos ratos submetidos ao autotransmplante no retroperitônio, não autoriza a afirmação de que este seja o local ideal, mas define como um local adequado para a colocação de um implante de baço, deixando em dúvida 
uma resposta para uma etapa posterior, que seria o estudo por imagem de um órgão parenquimatoso sobre uma estrutura totalmente muscular e que, talvez a aplicação de testes clínicos possam realmente avaliar a função do implante de forma mais objetiva e concretamente mensurável. Além do local ser, aparentemente adequado, pois todos os autotransplantes mostraram-se totalmente viáveis, tanto do ponto de vista operatório na inclusão e na retirada, quanto ao acesso, não havendo o desenvolvimento de qualquer complicação visível ou perceptível em qualquer dos animais estudados, esta observação possibilitaria o estudo funcional do implante, pois torna-o de fácil acesso na cavidade abdominal. Além destas dúvidas, surgem outras, diretamente relacionadas com o estudo, como com uma amostra maior os resultados poderiam ser diferentes? Esta pergunta continua a causar interesse pois na literatura consultada há relatos de que este local é inadequado, porém, não se encontrou nenhum estudo completo sobre este tema com auto-implante no retroperitônio. Vê-se com isto que este assunto é atual, continua a despertar interesse e ainda carece de muitas respostas para que uma conclusão definitiva seja emitida e possa ser recomendada a utilização do autotransplante em seres humanos independente da localização do mesmo.

\section{Conclusão}

O autotransplante de baço não demonstrou proteção efetiva contra sepse abdominal em comparação aos ratos esplenectomizados neste estudo.

\section{Referências}

1. Feliciano DV, Bitondo CG, Mattox KL, el al. A four-year experience with splenectomy versus splenorrhafy. Ann Surg. 1985; 201: 568-75.

2. Shandling B. Splenectomy for trauma a second look. Arch Surg. 1976; 111(12):1325-6.

3. Morris DH, Bullock FD. The importance of the spleen in resistence to infection. Ann Surg. 1919; 70: 513-21.

4. Sumaraju V, Smith LG, Smith SM. Infectious complications in asplenic hosts. Infect Dis Clin North Am. 2001; 15(2): 551-64.

5. King H, Shumacker HB. Splenic studies susceptibility to infection after splenectomy performed in infancy. Ann Surg. 1952; 85: 530-3.

6. Pabst R, Westermann J, Rothkotter HJ. Immunoarchtecture of regeneratedsplenic and lymphonode transplants. Int Rev Cytol. 1991; 128: 215-60.

7. Iinuma H, Okinaga K, Sato S, Tomioka M, Matsumoto K. Optimal site and amount of splenic tissue for autotranplantation. J Surg Res.1992; 53: 109-16.

8. Lemans R, Harms G, Rijkers GT, Timens W. Spleen autotransplantation provides restoration of functional splenic lymphoid compartments and improves the humoral immune response to pneumococcal polysaccharide vaccine. Clin Exp Immunol. 1999; 117: 596-604.

9. Pabst R, Kamran D. Autotransplantation of splenic tissue. J Pediatr Surg. 1986: 21: 120-4.

10. Patel JM, Willians JS, Nain JO, Hinshaw JR. The effect of site and technique of splenic tissue reimplantation on pneumococcal clearance from the blood. J Pediatr Surg. 1986;21: 877-80.

11. Torres OJM, Dietz AV, Lima JB, Loddo G, Salazar RM, Malafaia O. Histological evaluation of the regeneration of splenic autotransplants: experimental study in rats. Act Cir Bras. 1994; 9(2): 81-7.

12. Holdsworth RJ, Neill GD, Irving AD, Cuschieri A. Blood clearance and tissue distribution of ${ }^{99} \mathrm{Tc}$-labelled pneumococci following splenectomy in rabbits. Br J Exp Pathol. 1989; 70: 669-77.

13. Goldthorn JF, Schwartz AD, Swift AJ,Winkelstein JA. Protective effect of residual splenic tissue after subtotal splenectomy. J Pediatr Surg. 1978; 13: 587-90.

14. Touloukian RJ, Dang CV, Caride VJ. Splenic function following splendearterialization injury in suckling rat. J Pediatr Surg 1978; 13: 131-135.

15. Likhite VV. Protection agaist fulminant sepsis in splenectomized mice by implantation of autochthonous splenic tissue. Exp Hematol. 1978; 6: 433-9.

16. Drew PA, Clayer MT, Jamieson GG. The value of splenic autotransplantation. Arch Surg. 1990. 125(9): 1224.

17. Patel J, Willians JJ, Shmigel B, Hinshaw JR. Preservation of splenic function by autotransplantation of traumatized spleen in man. Surgery. 1981; 90(4): 683-8.

18. Willfuhr KU,Westermann J, Pabst R. Splenic autotransplantation provides protection against fatal sepsis in young but not in old rats. J Pediatr Surg. 1992; 27(9): 1207-12.

19. Livingston CD, LevineBA, Sirinek KR. Site of splenic autotransplantation affects protection from sepsis. Am J Surg. 1983; 146(6): 734-7.

20. Church JA, Mahour GH, Lipsey AI Antibody responses after splenectomy and splenic autoimplantation in rats. J Surg Res. 1981; 31(4): 343-6.

21. Petroianu A, Simal CJR, Barbosa AJA. Assessment of phagocytic function in remnants of subtotal splenectomy and in autologous spleen implantation. Med Sci Res. 1993; 21: 715-7.

22. Marques RG, Petroianu A. Auto-implante esplênico. ARS Cvrandi. 2002; 4:10-18.

23. Moore FA, moore EE, Moore GE, Erdoes L. Five fold enlargment of implants in a splenic autotransplant recipient. Surgery. 1993; 113: 462-5.

24. Marques RG, Petroianu A, Coelho JM. Bacterial phagocytosis by macrophage of autogenous splenic implant. Barz J Biol. 2003; 63(3): 491-5.

25. Vega A, Howell C, Krasna I, Campos J, Heyman S, Ziegler M. Splenic autotransplantation: optimal functional factors. J Pediatr Surg. 1981; 16:898-904.

26. Marques,RG, Petroianu A, Coelho JM, Portela MC. Regeneration of splenic autotransplants. Ann Hematol. 2002;81(11): 622-6.

27. Resende V, Petroianu A, Junior WCT. Autotransplantation for teatment of severe splenic lesions.Em Radiol. 2002; 9: 208-12.

28. Marques RG, Petroianu A, Coelho JMC. Regeneration of phagocytic function after splenic autotransplantation. Biom Res. 2003; 13(1): 15-8.

29. Smith E, De Young NJ, Drew PA. Decreased phagocitic capacity of autotransplanted splenic tissue. ANZ J Surg. 2003; 73(11): 894-6. 
30. Rice HM, James PD. Ectopic splenic tissue failed to prevent fatal pneumococcal septicemia after splenectomy for trauma. Lancet. 1980; 1: 565-6.

31. Moore GE, Stevens RE, Moore EE, Aragon GE. Failure of splenic implants to protect against fatal postsplenectomy infection. Am J Surg. 1983; 146: 413-4.
32. Westermann J, Pabst R. Autotransplantation of splenic fragments: lymphocyte subsets in blood, lymph nodes and splenic tissue. Clin Exp Immunol. 1986; 132: 191-6.

33. Kovacs K, Caride V, Touloukian RJ. Regeneration of splenic autotransplants in suckiling and adult rats. Arch Surg. 1981; 116: 335-6.

\section{Correspondência:}

Darlan de Medeiros Kestering

R. Antonina B. Corbeta, 167/301

88705-030 Tubarão - SC
Conflito de interesse: nenhum Fonte de financiamento: nenhuma

Recebimento: 22/05/2005

Revisão: 28/06/2005

Aprovação: 19/07/2005

\section{Como citar este artigo:}

Kestering DM, d'Acampora AJ, Farias DC, Brum SPB, Ely JB. Resistência de ratos à peritonite fecal quando submetidos a esplenectomia e auto-implante do baço no retroperitônio. Acta Cir Bras. [periódico na Internet] 2005 Nov-Dez;20(6). Disponível em URL: http://www.scielo.br/acb

*Figuras coloridas disponíveis em www.scielo.br/acb 